\title{
Identificação dos fluxos de escoamento superficial em área de relevo tecnogênico a partir do uso de modelos hidrológicos em SIG
}

\author{
Identification of run-off flow in area of technogenic relief by the use of \\ hydrologic models in SIG
}

\author{
Dener Toledo Mathias ${ }^{1}$ \\ Cenira Maria Lupinacci ${ }^{2}$ \\ João Osvaldo Rodrigues Nunes ${ }^{3}$ (D)
}

Palavras-chave:
Modelagem Hidrológica
Erosão Linear
Geotecnogênese

\begin{abstract}
Resumo
Este artigo apresenta os resultados do mapeamento das rotas de fluxo do escoamento superficial em área caracterizada por intensas modificações do relevo causadas por intervenções antrópicas. Como estudo de caso foi escolhida a alta bacia do córrego Tucum (São Pedro - SP), por apresentar um cenário marcado pelo avanço da urbanização sobre terrenos com forte suscetibilidade à erosão, com a presença de feições erosivas lineares (ravinas e voçorocas), e um complexo histórico de intervenções buscando o controle de tais processos. Foram utilizados dados primários, obtidos a partir de levantamento topográfico em campo, e executadas operações visando à elaboração de um Modelo Digital de Elevação Hidrologicamente Consistente (MDEHC), no programa ArcGIS 10.1. Em seguida, foi elaborada a Carta de Fluxo Concentrado da área, a partir da modelagem através do algoritmo Multiple Flow, no programa ArcView 3.2. Os resultados permitiram constatar que feições topográficas de detalhe, em especial, terraços tecnogênicos, têm exercido controle marcante sobre as rotas de fluxo do escoamento superficial, contribuindo para a geração de vetores de avanço erosivo das ravinas e voçorocas existentes na área.
\end{abstract}

\section{Keywords:}

Hydrological Modeling

Linear erosion

Geotechnogenesis

\begin{abstract}
This article presents the results of mapping the flow routes of surface runoff in an area characterized by profound changes in relief caused by anthropic interventions. We chose the Tucum stream upper basin (Sao Pedro, São Paulo - Brazil) as a case study because it is marked by the advance of urbanization on land with strong susceptibility to erosion, with the presence of linear erosive features (ravines and gullies) and a complex history of interventions seeking to control them. We obtained primary data from a topographic survey in the field and carried out operations to develop a
\end{abstract}

\footnotetext{
${ }^{1}$ Universidade Federal de Mato Grosso, Cuiabá, MT, Brasil. denertm@yahoo.com.br

${ }^{2}$ Universidade Estadual Paulista "Júlio de Mesquita Filho", Rio Claro, SP, Brasil, cenira.lupinacci@unesp.br ${ }^{3}$ Universidade Estadual Paulista "Júlio de Mesquita Filho", Presidente Prudente, SP, Brasil, joao.o.nunes@unesp.br
} 
Hydrologically Consistent Digital Elevation Model (HCDEM) in the ArcGIS 10.1 program. Then, the Concentrated Flow Map of the area was elaborated from the modeling using the Multiple Flow algorithm in the ArcView 3.2 program. The results showed that topographic features of detail, especially technogenic terraces, have exercised marked control over the flow routes of surface runoff, contributing to generating erosive advance vectors of the ravines and gullies.

\section{INTRODUÇÃO}

Dentre os mecanismos envolvidos na morfogênese, o escoamento superficial figura como agente hidrológico de grande repercussão. Em ambientes sob o imperativo do clima quente e úmido, a descarga hídrica proveniente das precipitações atua na esculturação do relevo de forma proeminente, resultando em força motriz para o desencadeamento de processos erosivos.

Diversos fatores atuam em conjunto definindo os padrões do escoamento superficial em uma dada paisagem. Segundo Bigarella et al (1996, p. 890) “as condições climáticas, as características morfométricas, as condições bióticas e edafológicas e as atividades antrópicas" são determinantes no comportamento do deflúvio. O autor aponta ainda que parte do fluxo irá infiltrar no solo integrando-se à rede de escoamento em subsuperfície e que, a partir da saturação do solo o fluxo passará a escoar predominantemente na superfície.

Dado o início do processo de escoamento superficial, o fluxo se configurará como laminar, em filetes, em lençol ou linear. A este último é atribuído o potencial de ocasionar incisões no terreno, sobretudo se as condições físicas já mencionadas contribuírem para a intensificação erosiva. Desse fato pode resultar a formação de sulcos, ravinas e voçorocas, que são canais incisos em diferentes estágios de evolução. As voçorocas constituem feições de dinâmica complexa, mas que são geradas e/ou potencializadas pelo fluxo do escoamento linear concentrado (BIGARELLA et al., 1996; FENDRICH, 1997; GUERRA, 2010).

Em relação aos fatores condicionantes ao desencadeamento erosivo, destacam-se as características físicas da paisagem, estando envolvidos principalmente os atributos geológicos, pedológicos, geomorfológicos, a cobertura vegetal e o clima. A topografia se constitui fator determinante no comportamento hidrológico das vertentes, uma vez que a morfometria reflete a energia potencial do escoamento superficial, enquanto a morfografia responde pela distribuição/concentração dos fluxos desse escoamento. Ao elemento relevo soma-se a influência antrópica, que atua como agente catalizador, seja através do manejo inadequado do solo, ou da expansão das áreas urbanas sem o devido planejamento (BRYAN, 2000; KIRKBY; BRACKEN, 2009; LIMA, 2003; OLIVEIRA, 2010; POESEN et al., 2003; VALENTIN et al., 2005).

Nos estudos sobre a dinâmica de processos erosivos, a geração de modelos digitais que incorporem a informação hidrológica em sua matriz, são indispensáveis. Essa prerrogativa se baseia no fato de que a rede de drenagem consiste no elemento do sistema físico em que se dá a maior parte do transporte de matéria e energia, sendo determinante nos processos morfogenéticos (CHRISTOFOLETTI, 1980).

Os fluxos de escoamento superficial são um componente fundamental para a análise dos processos geomorfológicos. Conforme aponta Coelho (2001, p. 95), "As rotas preferenciais dos fluxos superficiais ou subsuperficiais definem os mecanismos erosivo-deposicionais preponderantes". Nesse sentido, a identificação e mapeamento de tais rotas em áreas sujeitas ao desencadeamento de processos de erosão linear constituem procedimentos de grande valia no diagnóstico da dinâmica erosiva bem como no prognóstico evolutivo das feições (ASADI et al., 2007; CHAPLOT, 2005; HAIRSINE; ROSE, 1992; QUINN, 1991; PAISANI; OLIVEIRA, 2017; TAROLLI, 2014)

Este trabalho objetiva apresentar o mapeamento das rotas de fluxo superficial em área caracterizada pela presença de feições de relevo tecnogênico. Têm-se como premissa que o reconhecimento dos caminhos preferenciais do fluxo do escoamento permite a identificação de possíveis vetores de avanço das feições lineares, contribuindo para o prognóstico evolutivo dos processos.

\section{ÁREA DE ESTUDO}

Para o desenvolvimento deste estudo foi escolhida a alta bacia do córrego Tucum, localizada no 
município de São Pedro, região central do Estado de São Paulo (Figura 1). A área possui feições erosivas ocorrendo na periferia da malha urbana do município.

Figura 1 - Localização da alta bacia do córrego Tucum (São Pedro-SP).

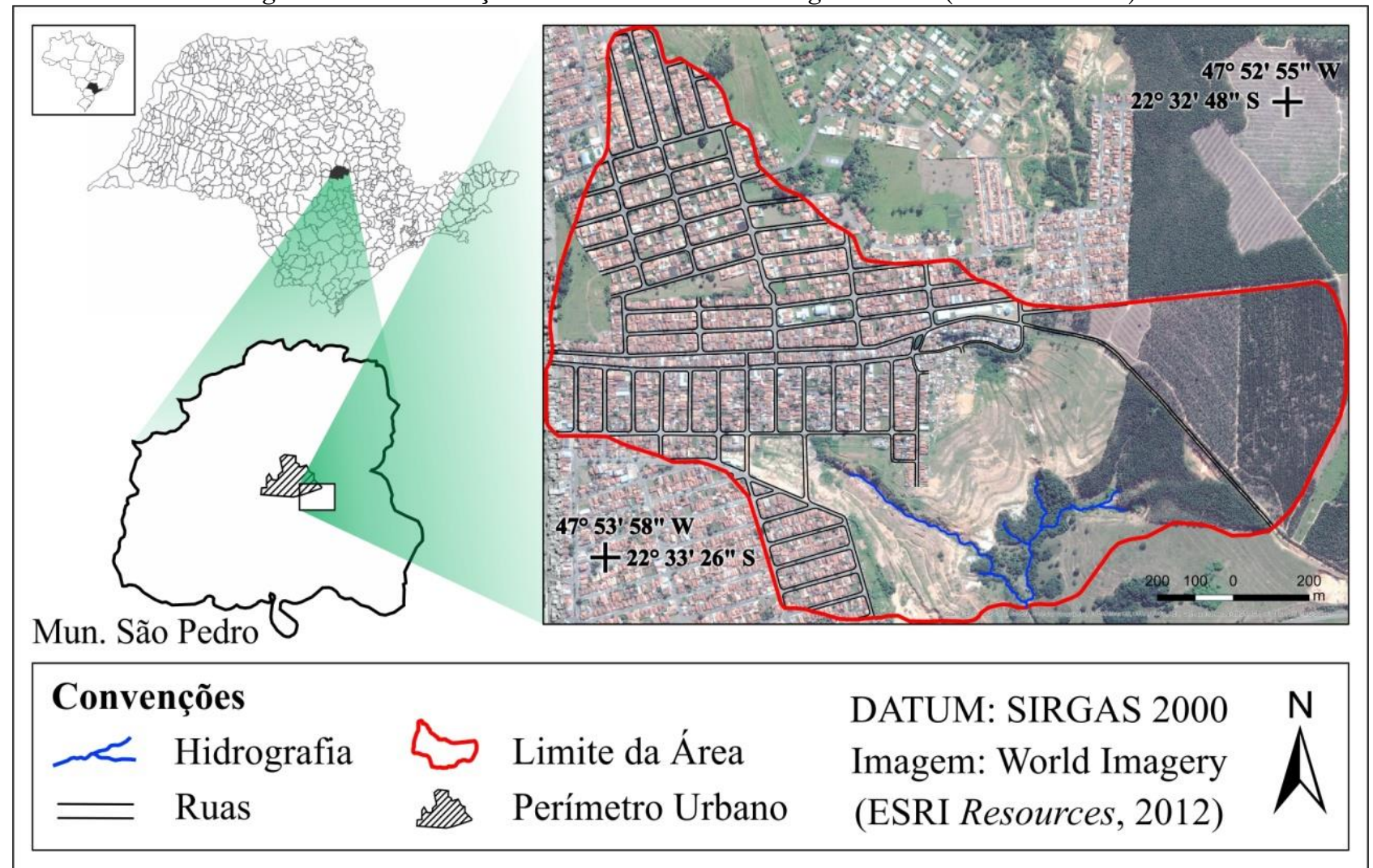

Org.: dos autores, 2019.

A alta bacia do córrego Tucum está inserida no compartimento morfoescultural da Depressão Periférica Paulista, constituindo parte da morfoestrutura da Bacia Sedimentar do Paraná. Possui, como arcabouço geológico, rochas areníticas das formações Pirambóia e Botucatu (datadas do Triássico e Jurássico-Cretáceo, respectivamente), sendo a primeira predominante na área de estudo (IPT, 1981). Há também a presença de coberturas neocenozóicas da Formação Rio Claro, que ocorrem de forma modesta capeando os interflúvios. As litologias têm, como atributo, forte friabilidade e os solos que se desenvolveram sobre elas (Argissolos e Neossolos Quartzarênicos), possuem granulometria de média a arenosa, sendo suscetíveis à erosão (CARPI JUNIOR, 1996; SANCHEZ, 1971). Estes solos são pobres em nutrientes, devido à forte lixiviação típica destas coberturas pedológicas (OLIVEIRA, 1999).

O relevo na alta bacia do córrego Tucum compõe-se de colinas amplas e topos com predomínio da forma tabular. As vertentes apresentam relevante comprimento de rampa, sendo que cedem abruptamente às margens dos córregos onde tem lugar a dinâmica erosiva atuante. Carpi Junior e Mendes (1992), identificam os relevos da área do córrego Tucum como pertencentes a duas unidades de compartimentação geomorfológica: Pedimentos Tabuliformes e Pedimentos Dissecados. Os autores observam que esses compartimentos são os mais suscetíveis à dinamização erosiva na região de São Pedro.

Aspectos relevantes acerca da área se relacionam ao uso da terra e a intervenções antrópicas efetuadas em diferentes escalas de espaço e tempo. É predominante o avanço da urbanização sobre áreas de uso pretérito agropastoril, que apresentam pastagens degradadas pontuadas com manchas de solo exposto. Ocorre ainda, em setores restritos, a silvicultura de eucaliptos. Convém ressaltar que a área, em sua totalidade, era ocupada por pastagens antes dos processos de urbanização referidos.

Em relação às intervenções antrópicas, se observam alterações produzidas por obras de controle dos processos erosivos. Essas intervenções foram efetuadas desde o início da 
expansão urbana na bacia, ocorrida em meados da década de 1960. Terraços em nível são encontrados nos setores de vertente entre a malha urbana e o curso fluvial. Depósitos tecnogênicos ocorrem nos setores de cabeceira da erosão, evidenciando tentativas de obliteração das formas erosivas com materiais de aterro (solos remobilizados) e resíduos sólidos urbanos.

Portanto, as características físicas da bacia propiciam condições para o desencadeamento erosivo, o que combinado aos fatores antrópicos (manejo inadequado da terra, avanço da urbanização sobre áreas de fragilidade e deposição indevida de resíduos) promove a intensificação dos processos erosivos. As intervenções visando mitigar o avanço das feições erosivas se evidenciam como inadequadas, uma vez que consistiram apenas no soterramento das ravinas e voçorocas e no terraceamento da área (MATHIAS, 2016). Assim, o condicionamento imposto pelas feições tecnogênicas no comportamento hidrológico da área justifica um estudo mais detalhado a partir das técnicas de mapeamento adotadas neste trabalho.

\section{MATERIAL E MÉTODOS}

Com o intuito de mapear as rotas de fluxo do escoamento superficial na área de estudo, foram adotadas operações de processamento em ambiente SIG, utilizando o programa ArcGIS 10.1. Tendo como premissa que as feições de detalhe do relevo são significativas na determinação das rotas de fluxo e, consequentemente, nos processos atuantes em áreas de suscetibilidade erosiva (caracterizadas ainda por intensas intervenções antrópicas), foi realizado um levantamento topográfico objetivando a aquisição de dados em nível de detalhe. $\mathrm{O}$ equipamento utilizado para tanto foi uma Estação Total, de marca Ruide, modelo RTS 825 R3. A partir do levantamento efetuado em campo, foram obtidos 13648 pontos mensurados por irradiação de 98 estações, sendo a área do polígono resultante de $621491 \mathrm{~m}^{2}$.

O processamento dos dados foi executado utilizando-se os recursos do programa Autodesk Land 2004 e resultou na extração de uma malha de pontos contendo as coordenadas planialtimétricas. $\mathrm{O}$ georreferenciamento dos dados topográficos se deu por duas coordenadas obtidas em campo com GPS de precisão (modelo: L1/L2 RTK Leica / GS15 Viva), as quais foram incorporadas ao levantamento no instante do processamento dos dados.
Cabe ressaltar que nos trabalhos de levantamento foi dada atenção especial às feições de relevo tecnogênicas, as quais foram mensuradas detalhadamente. De igual modo foram levantados pontos ao longo dos rebordos das formas erosivas e nos fundos de vale, para obter uma representação pormenorizada das incisões e suas ramificações.

A malha de pontos georreferenciada foi transcrita da extensão gerada pelo Autocad para o formato de shapefile, a fim de ser trabalhada no programa ArcGIS 10.1. Em seguida gerou-se uma grade triangular TIN (Triangulated Irregular Network), resultando em um Modelo Digital do Terreno (MDT) que viabilizou a geração de uma base cartográfica em escala de 1:500, com equidistância das curvas de nível de $1 \mathrm{~m}$.

A escolha do método de grade triangular se pautou nas características da malha de pontos, que apresentava variações de densidade resultantes de uma maior amostragem em setores de maior complexidade morfológica, como no caso das formas de retrabalhamento contidas no interior das incisões erosivas. Também foi levada em consideração a possibilidade da realização de edições sobre o TIN, com base na reambulação de dados a partir de observações de campo posteriores à geração do MDT. Adotou-se como premissa que somente dados topográficos em nível de detalhe permitem avaliar criteriosamente certos fenômenos, como no caso da erosão (TAROLLI, 2014).

Contando com o MDT, procedeu-se a uma série de etapas importantes para o refinamento dos dados e o mapeamento das rotas de fluxo do escoamento superficial. Tais etapas se iniciam com a identificação e enriquecimento da rede de drenagem, cuja premissa foi a inclusão dos traçados de canais de concentração do fluxo pluvial. Conforme orientação contida em tutorial on-line oferecido pela empresa ESRI (2013), utiliza-se a ferramenta Hidrology da Toolbox Spatial Analyst, cujos algoritmos permitem a extração da rede de drenagem em diferentes níveis hierárquicos, definidos em função da necessidade da análise.

A sequência operacional adotada pode ser resumida nas seguintes etapas: a) Fill preenchimento de vazios resultantes da concepção do modelo digital; b) Flow Direction - elaboração de um modelo contendo as direções dos fluxos de escoamento; c) Flow Accumulation - mapeamento dos possíveis canais de concentração do fluxo do escoamento, com base em algoritmo multidirecional (que considera o valor acumulado do escoamento em cada célula do modelo em função das células precedentes a montante). A 
conclusão do procedimento foi realizada por meio do comando Raster Calculator, a partir do qual se gera um arquivo contendo o traçado da rede de drenagem, que por sua vez é convertido em formato shapefile, com o uso do comando Stream to Feature.

$\mathrm{Na}$ etapa seguinte foi gerado um Modelo Digital de Elevação Hidrologicamente Consistente (MDEHC), conforme proposto por Chaves (2002). No procedimento é utilizado o interpolador Topo To Raster, componente da toolbox Spatial Analyst, que é considerado como o mais adequado para essa finalidade uma vez que permite integrar a drenagem no processo de interpolação (GUEDES et al., 2011; RIBEIRO, 2015; VALERIANO, 2004).

Seguindo os procedimentos contidos no tutorial on-line da ESRI (2013), foram interpoladas as seguintes feições: a) curvas de nível, com equidistância de 1 metro; b) rede de drenagem (incluindo-se os canais de escoamento gerados conforme já descrito); c) limite da área, como polígono delimitador da interpolação. A resolução espacial, inserida como um dos parâmetros de interpolação, foi definida após uma série de testes cujo resultado de melhor acurácia mostrou ser aquele obtido com pixels de $0,5 \mathrm{~m}$ de lado (cada pixel equivale a uma área de $0,25 \mathrm{~m}^{2}$ ), sendo, portanto, o MDEHC na escala de 1:1000. A relação entre escala e resolução se enquadra nos valores previstos no Padrão de Exatidão Cartográfica dos Produtos Cartográficos Digitais (PEC-PCD), estabelecidos pela Especificação Técnica dos Produtos de Conjuntos de Dados Geoespaciais (ET-PCDG), segundo o Decreto $\mathrm{n}^{\circ}$ 89.817 (BRASIL, 1984). Convém ressaltar que os dados topográficos contemplavam feições de detalhe, tais como formas erosivas de retrabalhamento, o que justifica a resolução em escala centimétrica.

A etapa final do trabalho consistiu em operação visando elaborar um mapa que pudesse representar o percurso preferencial do fluxo do escoamento superficial, delimitando-se os setores de dispersão de águas e os de maior concentração. A Carta de Fluxo Acumulado (Flow Accumulation) constitui um documento de grande valia às análises propostas neste estudo.

O procedimento adotado para a obtenção da Carta de Fluxo Acumulado é explicitado por Fontes (2009), tendo sido utilizado em diversos trabalhos (BARBOSA, 2011; MATHIAS, 2011; MORAES et al., 2014). A técnica baseia-se nas proposições de Schäuble (2004) e consiste no cálculo numérico das células de um modelo digital, voltado à representação de valores de concentração por área de contribuição, ou seja, são computadas as relações geométricas entre as células do modelo a fim de obter-se a quantidade em área $\left(\mathrm{m}^{2}\right)$, que drena para cada célula individualmente.

A referida técnica se destaca por apropriar-se do algoritmo de fluxo múltiplo, desenvolvido por Quinn et al (1991), a partir do qual o cálculo se dá em múltiplas direções. O algoritmo é definido com base no índice de acumulação do fluxo (In) conforme a Equação 1.

$\operatorname{In}=\ln (\alpha / \operatorname{tang} \beta)$

Em que: $\alpha$ é a área de captação específica ( $\left.\mathrm{L}^{2} / \mathrm{L}\right)$, dada pela somatória da área de contribuição a montante, L é a unidade genérica de comprimento e tang $\beta$ é a inclinação da rampa. Conforme explicitado por Moraes et al (2014, p. 226), o índice topográfico In se refere "à tendência da água se acumular em $\alpha$, sendo tang $\beta$ o termo que considera as forças gravitacionais, como um gradiente hidráulico aproximado". O cálculo visa analisar as vias de fluxo, determinando sua direção. Também participam valores de inclinação, ponderados a partir dos $n$ valores dos ângulos de cada grid, a partir da soma dos comprimentos ortogonais (QUINN et al., 1991 apud MORAES et al., 2014).

O algoritmo permite que a área de aclive acumulado de uma dada célula seja distribuída entre todos os sentidos da vertente, sendo capaz de contribuir para jusante em até oito direções de fluxo possíveis. De acordo com Quinn et al (1991, apud MORAES et al, 2014, p. 224), cada direção da curva descendente é feita "proporcional ao gradiente de percurso de escoamento a jusante, combinado com o comprimento da rampa e a área drenada à montante". Como resultado, obtém-se um mapa que pode ser classificado de acordo com classes representativas visando a identificação das tendências de concentração do escoamento.

Para geração da Carta de Fluxo Acumulado foram adotadas as orientações apresentadas por Fontes (2009), que utiliza o programa ArcView 3.2. As operações para obtenção do mapa se dão pela ferramenta Hydrotools, que deve ser instalada como complemento do programa. A extensão Spatial Analyst também deve estar ativada para que o programa possa fazer a leitura do grid de um arquivo raster.

Tendo adicionado o arquivo correspondente ao MDEHC, procedeu-se à preparação da superfície, na qual é gerado um grid das direções de fluxo (Flow Direction); em seguida realizou-se operação para correção de possíveis erros do modelo (DEM Correction) e, por fim, dentro da funcionalidade Hidrology, realizou-se a operação Flow 
Accumulation. Nessa etapa define-se o algoritmo utilizado que, no caso deste estudo, foi o MD (Multiple Flow), em conformidade com as proposições de Fontes (2009).

$\mathrm{O}$ grid gerado corresponde ao mapa representando as tendências de acumulação/dispersão do escoamento. Assim, fazse a exportação do mesmo para que possa ser inserido na base de dados do ArcGIS 10.1, cuja interface permite a reclassificação da imagem em intervalos definidos de acordo com a necessidade do trabalho. Neste estudo foram definidos intervalos em escala geométrica em $\mathrm{m}^{2}(5,10,50$, 100, 500, 1000), por permitirem a visualização mais adequada dos dados. Somente o último intervalo de classe é que engloba os valores maiores gerados pelo programa (intervalo de 1000 $\mathrm{m}^{2}$ a $1761045 \mathrm{~m}^{2}$ ), no qual estão contidos apenas os valores das células correspondentes ao traçado da rede de drenagem.

A Figura 2 (organizada pelos autores) apresenta o organograma para geração da Carta de Fluxo Acumulado.

Figura 2 - Procedimentos para a geração da Carta de Fluxo Acumulado

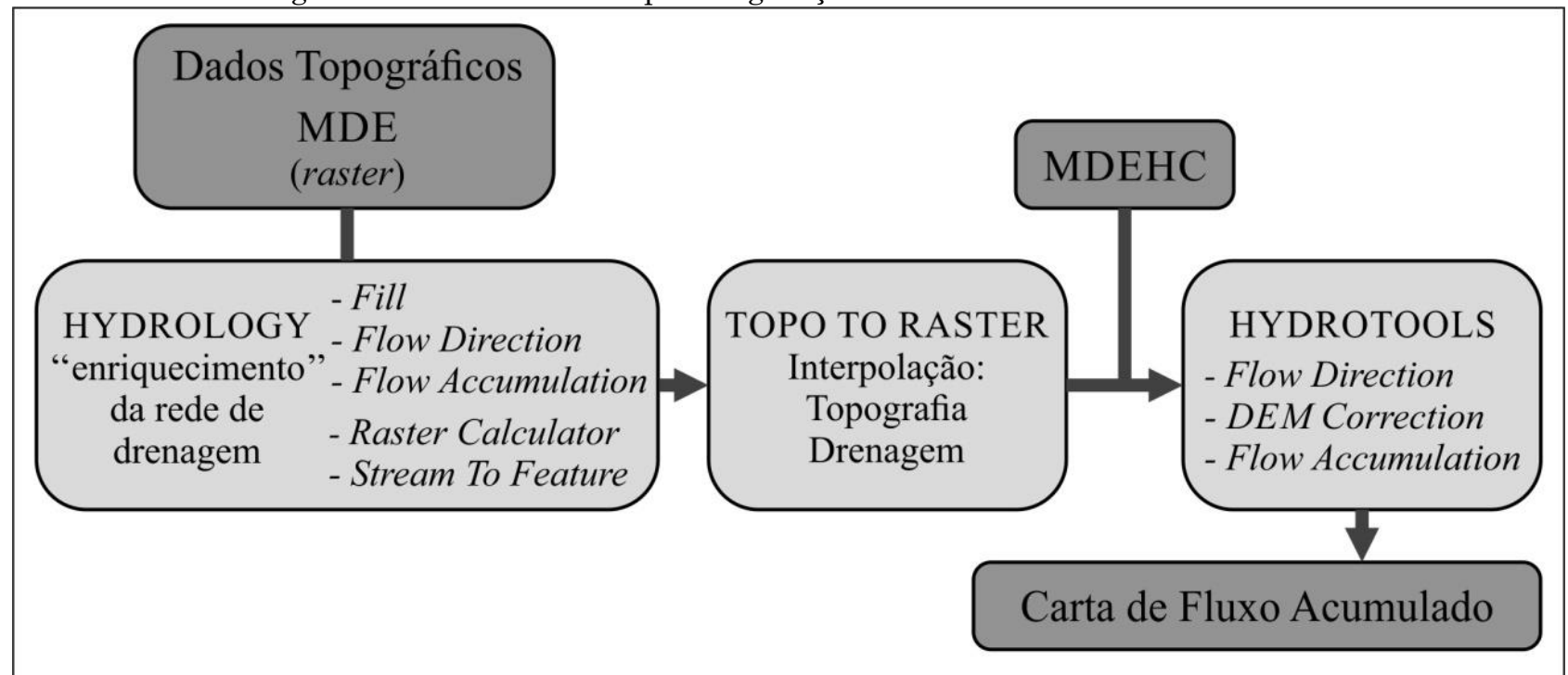

Org.: dos autores, 2019.

Foram realizados trabalhos de campo para reconhecimento das feições e, sobretudo, averiguação e checagem dos dados gerados, com o intuito de verificar a validade do produto cartográfico final. As atividades de campo foram efetuadas espaçadamente no período entre os meses de janeiro e março de 2015, perfazendo um total de 15 dias. A checagem foi pautada em análise visual tanto de sulcos erosivos como de "bolsões" de acumulação de sedimentos na vertente, resultantes do transporte pelos fluxos do escoamento superficial, os quais corroboraram as rotas de fluxo mapeadas.

Após a geração da Carta de Fluxo Acumulado, foi elaborado um modelo tridimensional através do programa ArcScene 10.1, a partir da sobreposição do mapa em extensão raster ao MDE. Também foi inserido o desenho vetorial de uma linha representando a borda do talude erosivo. Estes procedimentos foram realizados para auxiliar o processo de análise dos produtos cartográficos, assim como para a composição das imagens que ilustram este artigo.

\section{RESULTADOS E DISCUSSÕES}

A análise da Carta de Fluxo Acumulado da alta bacia do córrego Tucum permite constatar que o comportamento do fluxo de escoamento superficial nas vertentes periurbanas obedece à forte controle das feições topográficas, sendo condicionado principalmente por terraços tecnogênicos. Os traçados do fluxo concentrado se evidenciam como possíveis vetores de avanço erosivo, sobretudo nos rebordos das ravinas e voçorocas existentes na área.

A Figura 3 (organizada pelos autores) apresenta o recorte do setor sudoeste da Carta de Fluxo Acumulado da Alta Bacia do Córrego Tucum, com detalhes em perspectiva gerados no programa ArcScene 10.1.

Figura 3 - Setor SW da área de estudo, com detalhes em visualização 3D (detalhes A e B). 


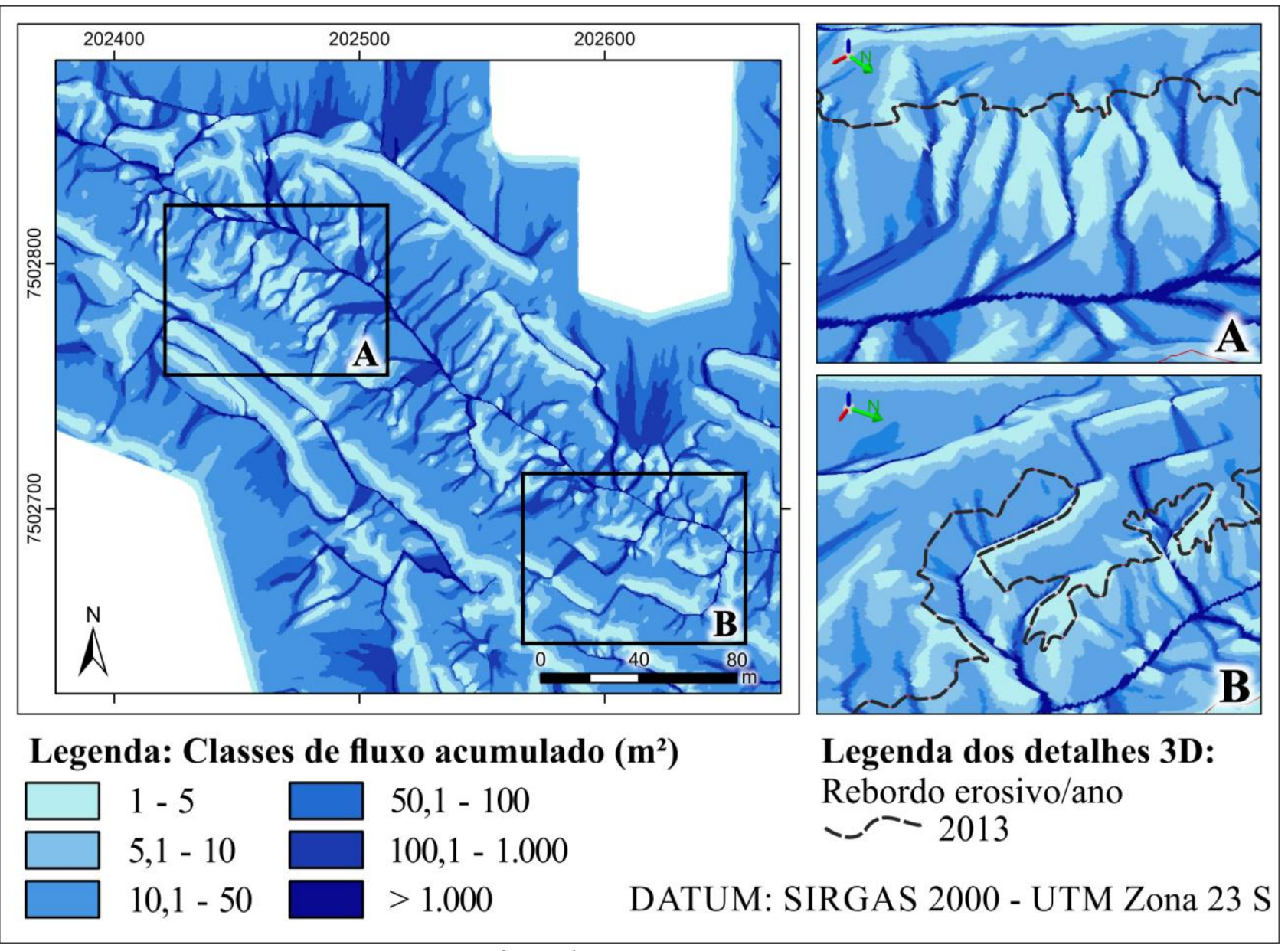

Org.: dos autores, 2019.

O setor sudoeste da alta bacia do córrego Tucum se caracteriza pela presença de uma voçoroca de dimensões notáveis, contendo em seus taludes uma profusão de ramificações na forma de sulcos e ravinas. As feições topográficas existentes nas vertentes que bordejam a citada voçoroca, em especial os terraços tecnogênicos, exercem controle significativo sobre as rotas de fluxo do escoamento superficial, em alguns casos impedindo o avanço remontante da erosão e em outros casos contribuindo para tanto.

As imagens tridimensionais apresentadas na Figura 3 são representativas de duas situações distintas que podem ser identificadas a partir dos resultados. Em A é possível constatar a concentração dos fluxos lineares no interior de sulcos erosivos existentes em talude de voçoroca. Tais fluxos são contribuintes na progressão de ramificações na citada feição, embora as rotas tenham comprimento limitado, haja vista a existência de um terraço à montante. Assim, apesar da profusão de sulcos e entressulcos, observou-se que o avanço erosivo neste ponto do talude é menos pronunciado, de acordo com monitoramento efetuado por Mathias (2016). O aprofundamento dos sulcos é mais expressivo que o seu avanço para montante. A Figura 4a apresenta a fotografia do setor de talude onde ocorre grande quantidade de sulcos e ravinas.

No detalhe B (Figura 3) se verifica uma situação diferente da anterior. Nesse caso a presença de terraços potencializa os efeitos da erosão, pois ocorre o condicionamento das rotas de fluxo do escoamento e sua concentração em canais existentes no reverso dos terraços. Quando há o rompimento do terraço (ocasionado pelo avanço erosivo remontante), o fluxo passa a contribuir na incisão do terreno criando uma ravina que progride no sentido da rota do escoamento concentrado. O processo ganha potencial devido ao desnível do talude na cabeceira da feição, o qual é marcado por alcovas de regressão em sua base. Trata-se, portanto, de um vetor erosivo identificado a partir dos resultados do mapeamento que permitem prever a evolução espacial das feições. A Figura $4 \mathrm{~b}$ apresenta fotografia aérea panorâmica da área, com detalhe para as ravinas formadas. 
Figuras 4a e 4b - Talude de voçoroca com ampla difusão de sulcos erosivos e ravinamentos laterais formados após rompimento de terraço, respectivamente.

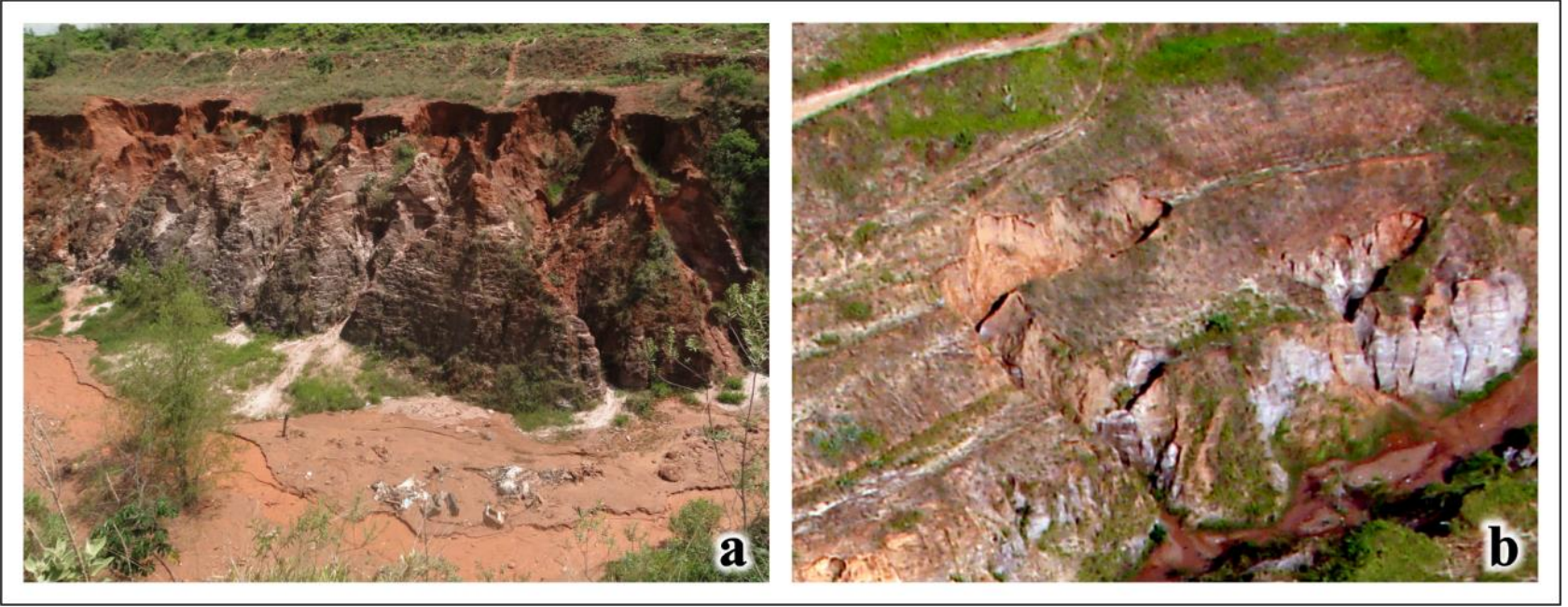

Org.: dos autores, 2019.

A Figura 5 (elaborada pelos autores) apresenta o recorte do setor sudeste da Carta de Fluxo Acumulado da Alta Bacia do Córrego Tucum, acrescida igualmente de imagens tridimensionais de duas porções do terreno representativas no tocante às características do fluxo do escoamento e dos processos associados. Os terraços tecnogênicos desempenham papel importante no controle do escoamento superficial, produzindo respostas processuais à dinâmica erosiva ocorrente na área.

A análise da Figura 5 permite constatar que há um nítido contraste no comportamento do fluxo do escoamento superficial entre duas porções da área, delimitadas por uma estrada que a secciona transversalmente. Os terrenos que compõem a alta vertente não possuem terraços tecnogênicos (canto superior direito do recorte da carta), enquanto que a média e baixa vertentes são marcadas por essas feições.

A mencionada estrada, uma via municipal não pavimentada, consiste um caminho preferencial aos fluxos de escoamento no setor analisado, uma vez que é acompanhada de terraço em sua lateral. O deflúvio do escoamento para os terrenos mais baixos se dá em um único ponto (Figura 5A). No local nota-se em campo a presença de uma ravina cuja cabeceira está em contato com a estrada, assim representando fator de risco à população que utiliza esta via (Figura 6a).

Vias não pavimentadas além de constituir caminhos preferenciais ao escoamento concentrado são (por essa mesma razão) terrenos suscetíveis a intenso trabalho erosivo, sobretudo devido às condições impostas aos materiais superficiais pela circulação de veículos (compactação, pulverização). Conforme Thomaz e Ramos-Scharrón (2015), a erosão em estradas produz até 17 vezes mais sedimentos do que em áreas de uso agrícola, segundo estudo realizado no sul do Brasil.

$\mathrm{Na}$ Figura 5B é apresentada uma voçoroca existente nas porções de baixa vertente do setor sudeste. Os terraços tecnogênicos situados no contato com as bordas desta voçoroca, impõem um traçado ao escoamento, fazendo com que o fluxo concentrado desemboque na cabeceira de uma ramificação da citada feição erosiva. Esta é uma das feições de dinâmica mais pronunciada, conforme atestado em campo. Trata-se de uma condição peculiar em que estruturas concebidas com o intuito de evitar o avanço erosivo de cabeceira vêm a ocasionar a intensificação dos processos em área adjacente. A Figura 6b apresenta fotografia aérea panorâmica enfocando a voçoroca citada. 
Figura 5 - Setor SE da área de estudo, com detalhes em visualização 3D (detalhes A e B).

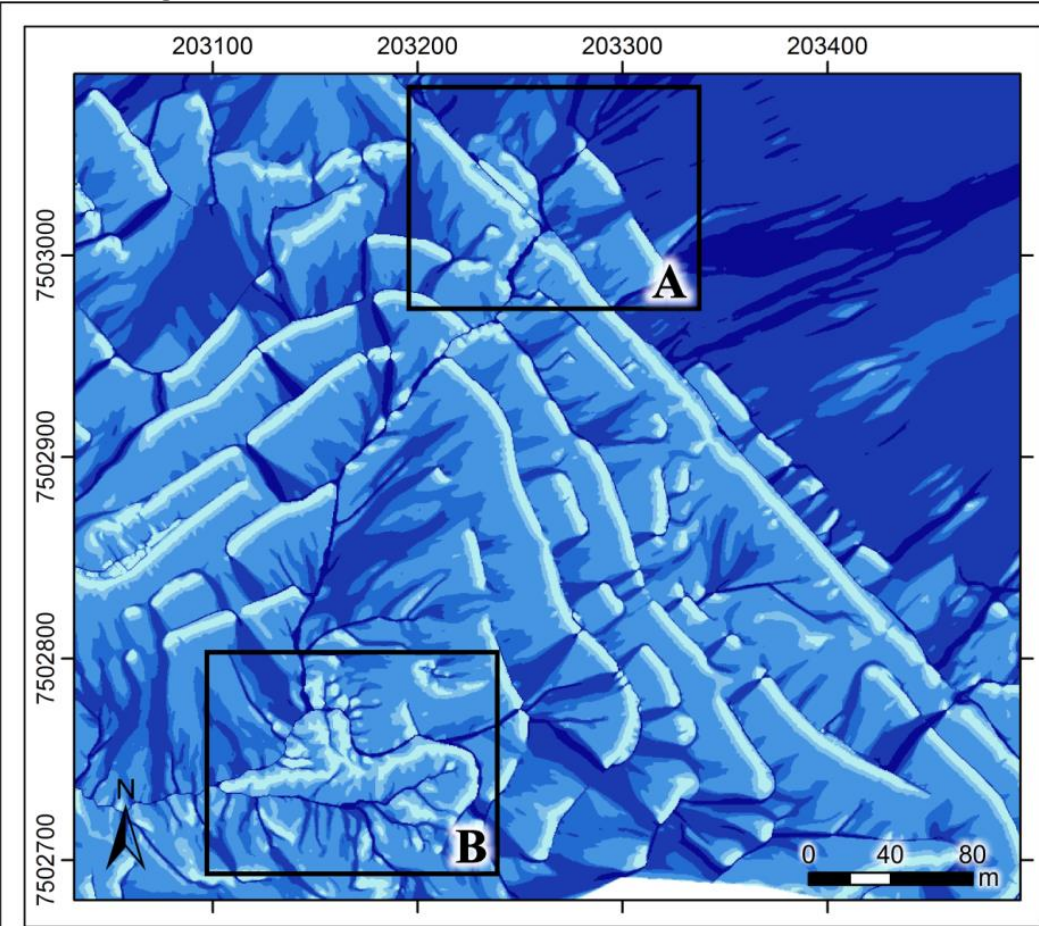

\section{Legenda: Classes de fluxo acumulado $\left(\mathrm{m}^{2}\right)$}

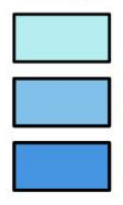

$1-5$

$5,1-10$

$10,1-50$ $\square 50,1-100$

$100,1-1.000$

$>1.000$
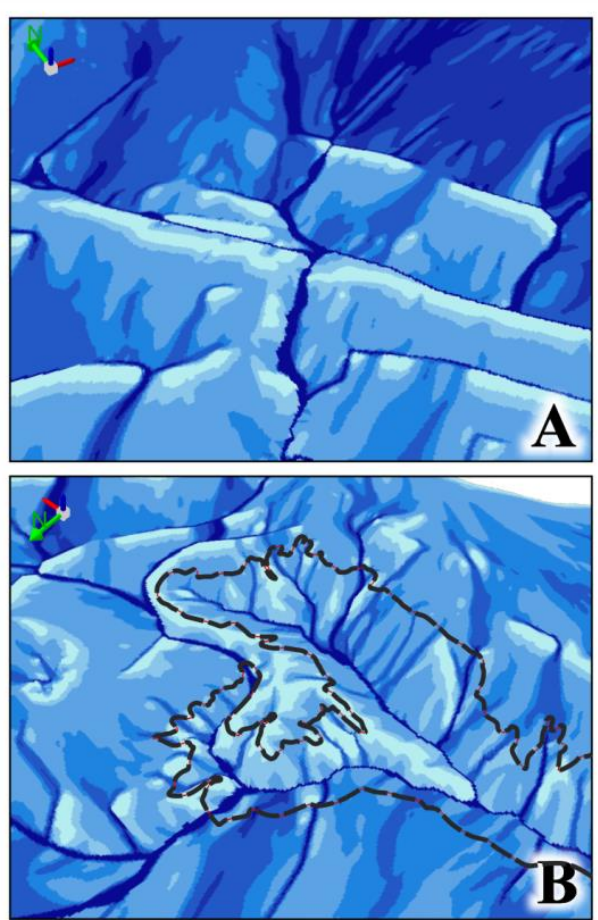

Legenda dos detalhes 3D:

Rebordo erosivo/ano

- ハ 2013

Org.: dos autores, 2019.

Figuras $6 \mathrm{a}$ e $6 \mathrm{~b}$ - Cabeceira de ravina em contato com via pública e voçoroca existente no setor sudeste da área de estudo, respectivamente.
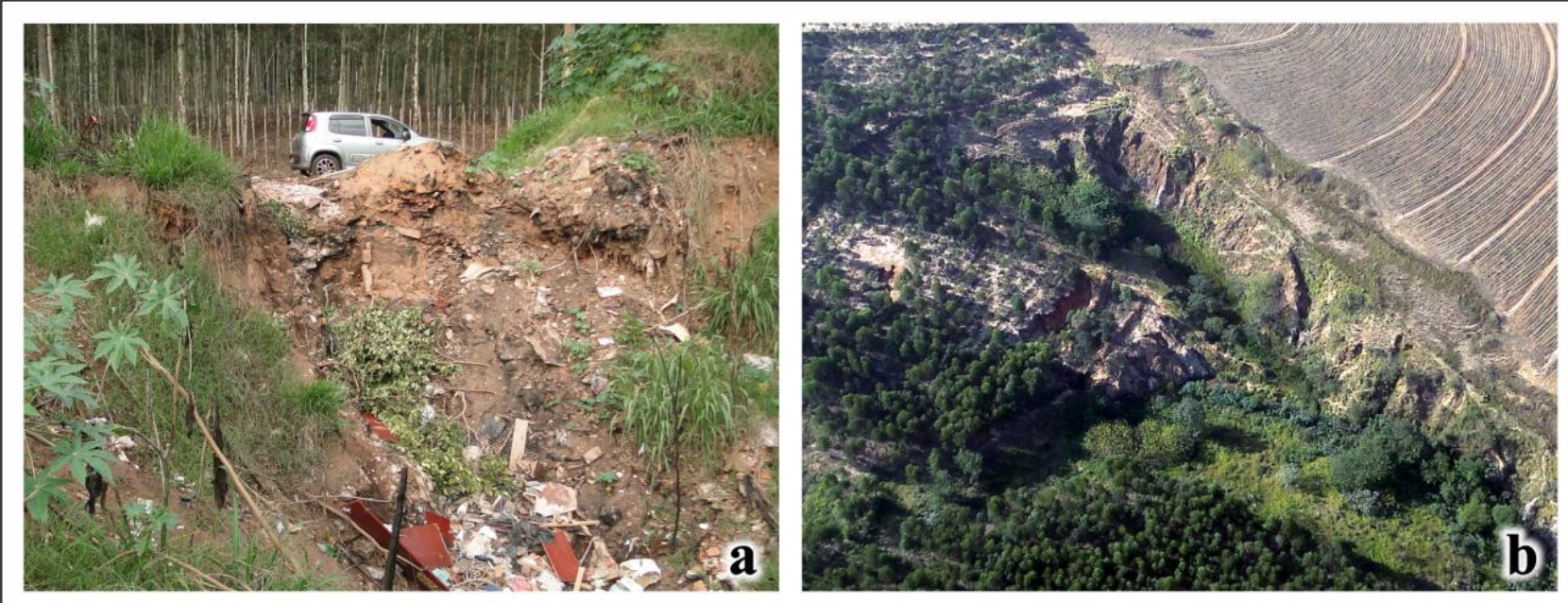

Org.: dos autores, 2019.

As análises efetuadas neste estudo encontram respaldo nas considerações de Ternan et al (2013), para os quais é evidente que os "bancos" gerados por terraceamento (benchterracing) configuram uma nova e complexa condição em superfície e subsuperfície, muito diferente daquela encontrada nas áreas com cobertura vegetacional que não foram submetidas a intervenções.

Os terraços tecnogênicos são, portanto, 
feições marcantes nas vertentes da alta bacia do córrego Tucum, sendo decorrentes de obras de terraceamento pretéritas efetuadas como medida de controle dos processos erosivos. A análise da Carta de Fluxo Acumulado da área de estudo permitiu identificar tais feições e relacioná-las às rotas de fluxo do escoamento. Observações realizadas em campo corroboram os dados apresentados, o que comprova a eficiência do referido documento cartográfico como instrumento útil ao diagnóstico dos processos e ao prognóstico evolutivo das formas erosivas.

\section{CONSIDERAÇÕES FINAIS}

A dinâmica de processos erosivos lineares está associada, dentre outros fatores, ao potencial inerente ao fluxo concentrado do escoamento, que pode ser elencado como um dos agentes na deflagração da erosão. O escoamento superficial por sua vez é condicionado às formas topográficas de detalhe, que irão determinar possíveis rotas de concentração do fluxo como linhas preferenciais à formação e crescimento de incisões no terreno.

Em áreas caracterizadas por forte suscetibilidade ao desencadeamento erosivo, as formas de uso e ocupação podem contribuir substancialmente com a dinamização dos processos. No caso da alta bacia do córrego Tucum, as acentuadas modificações promovidas pelo avanço da urbanização somam-se às sucessivas intervenções malsucedidas no sentido de controlar a erosão, seja mediante a obliteração das incisões com o soterramento pelo despejo de resíduos sólidos urbanos, como pela adoção de métodos da engenharia a exemplo dos terraceamentos.

As formas tecnogênicas geradas em diferentes ciclos de intervenções mostram-se no caso estudado como feições que contribuem para o aumento da complexidade com que se dão os processos erosivos. Isso se deve ao fato de que as feições podem controlar o avanço da erosão ou, sob outras condições, permitir a deflagração da mesma. Assim, a evolução das feições erosivas é fortemente condicionada por formas tecnogênicas, em geral responsáveis pela determinação das rotas de fluxo do escoamento superficial.

A abordagem realizada no presente estudo, pautada na elaboração de um documento cartográfico que mapeia, através da morfometria do relevo, as rotas de fluxo concentrado do escoamento superficial mostra-se útil ao estudo de processos erosivos, assim como às possíveis ações de gestores públicos. Portanto, os resultados obtidos neste trabalho contribuem com subsídios importantes às possíveis intervenções que possam ser efetuadas na área visando o controle dos processos erosivos. O trabalho contribui ainda com um exemplo da relevância de dados topográficos em detalhe, a partir da construção de uma base cartográfica adequada aos cenários de morfologias tecnogênicas.

\section{AGRADECIMENTOS}

Os autores agradecem à Fundação de Amparo à Pesquisa do Estado de São Paulo pelo fomento concedido (Processo FAPESP nº 03745-4).

\section{REFERÊNCIAS}

ASADI, H.; GHADIRI, H. ROSE, C. W.; ROUHIPOUR, H. Interrill soil erosion processes and their interaction on low slopes. Earth Surface Processes and Landforms, v. 32, n. 5, p. 711-724, 2007. https://doi.org/10.1002/esp.1426

BARBOSA, C. Planejamento urbano sustentável: diretrizes de urbanização embasadas nas características geomorfológicas/pedológicas de vertentes. 2010. 123 f. Dissertação (Mestrado em Geografia). Instituto de Geociências e Ciências Exatas, Universidade Estadual Paulista, Rio Claro, 2011.

BIGARELLA, J.J.; BECKER, R.D.; PASSOS, E. Estrutura e Origem da Paisagens Tropicais e Subtropicais. Ed. UFSC. V. 2, 1996. $875 \mathrm{p}$.

BRASIL. Decreto $\mathrm{n}^{\circ}$. 89.817, de 20 de junho de 1984. Dispõe sobre as instruções reguladoras das normas técnicas da cartografia nacional. Diário Oficial da República Federativa do Brasil, Brasília, 22 de junho de 1984.

BRYAN, R. B. Soil erodibility and processes of water erosion on hillslope. Geomorphology, v. 32 , n. 3-4, p. 385-415, 2000. https://doi.org/10.1016/S0169-555X(99)00105-1

CARPI JUNIOR, S; MENDES, I. A. As vertentes do córrego Tucum (São Pedro, SP) e seu significado morfogenético. Geografia, Rio Claro, 17(1): 77-90, 1992.

CARPI JUNIOR, S. Técnicas cartográficas aplicadas à dinâmica da bacia do Ribeirão Araquá - SP. 1996. 188 f. Dissertação (Mestrado em Geografia) - Instituto de Geociências e Ciências Exatas, Universidade 
Estadual Paulista, Rio Claro. 1996.

CHAPLOT, V.; GIBOIRE, G.; MARCHAND, P.; VALENTIN, C. Dynamic modelling for linear erosion initiation and development under climate and land-use changes in northern Laos. Catena, v. 63, n. 2-3, p. 318-328, 2005. https://doi.org/10.1016/j.catena.2005.06.008

CHAVES, $M$ de A. Modelos digitais de elevação hidrologicamente consistentes para a Bacia Amazônica, 2002. 115 f. Tese (Doutorado em Ciências Florestais). Universidade Federal de Viçosa: UFV, Viçosa, 2002.

CHRISTOFOLETTI, A. Geomorfologia, Edgard Blucher, São Paulo, 1980. 188 p.

COELHO, M. C. N. Impactos ambientais em áreas urbanas: teorias, conceitos e métodos de pesquisa. In: GUERRA, A. J. T. Impactos ambientais urbanos no Brasil. Rio de Janeiro: Bertrand Brasil, p. 19-45, 2001.

ESRI ArcGIS Resources. Version 10.1 Environmental Systems Research Institute, Inc. 2012. Disponível em: $<$ http://resources.arcgis.com/en/help/main/10.1/ >. Acesso em: 13 fevereiro 2020.

FENDRICH, R.; OBLADEN, N. L.; AISSE, M. M.; GARCIAS, C. M. Drenagem e controle da erosão urbana. Curitiba: Champagnat. $4^{a}$ ed., 1997, $486 \mathrm{p}$.

FONTES, N. Proposta Metodológica para planejamento de sistemas de espaços livres: Ribeirão Preto - SP. 2009. 193 f. Tese (Doutorado em Geografia). Instituto de Geociências e Ciências Exatas da Universidade Estadual Paulista, Rio Claro, 2009.

GUEDES, H. A. S.; CAPOBIANGO, G. V.; MARTINS, V. S.; SILVA, D. Análise da precisão entre os métodos de interpolação Krigagem Ordinária e Topo to Raster na geração de modelos digitais de elevação. In: XV SIMPÓSIO BRASILEIRO DE SENSORIAMENTO REMOTO. Anais... SBSR, Curitiba, PR, Brasil, INPE, 2011 p.4239.

GUERRA, A. J. T. O início do processo erosivo. In: GUERRA, A. J. T. et al (orgs), Erosão e conservação dos solos: conceitos, temas e aplicações, $2^{\text {a }}$ ed. Rio de Janeiro: Bertrand Brasil, 2010. p. 15-55.

HAIRSINE, P. B.; ROSE, C. W. Modeling water erosion due to overland flow using physical principles: 1. Sheet flow. Water resources research, v. 28, n. 1, p. 237-243, 1992. https://doi.org/10.1029/91WR02380

INSTITUTO DE PESQUISAS TECNOLÓGICAS DO ESTADO DE SÃO PAULO. 1981. Mapa geológico do Estado de São Paulo; escala 1:500.000. v1 (texto) e v2 (mapa). Governo do estado de São Paulo. Secretaria da Indústria, Comércio, Ciência e Tecnologia.

KIRKBY, M. J.; BRACKEN, L. J. Gully processes and gully dynamics. Earth Surface Processes and Landforms: The Journal of the British Geomorphological Research Group, v. 34, n. 14, p. 1841-1851, 2009. https://doi.org/10.1002/esp.1866

LIMA, E. R. V. de Erosão do solo: fatores condicionantes e modelagem matemática. Revista Cadernos do Logepa, v. 3, n. 1, p. 343, 2003.

MATHIAS, D. T. Propostas de recuperação de áreas peri-urbanas erodidas com base em parâmetros hidrológicos geomorfológicos: Córrego Tucunzinho (São Pedro/SP). 2011. 128 f. Dissertação (Mestrado em Geografia). Instituto de Geociências e Ciências Exatas, Universidade Estadual Paulista, Rio Claro, 2011.

Contribuição metodológica para o diagnóstico da dinâmica erosiva linear e seu prognóstico evolutivo visando subsidiar projetos de recuperação. 2016. 178 f. Tese (Doutorado em Geografia). Faculdade de Ciências e Tecnologia, Universidade Estadual Paulista, Presidente Prudente, 2016.

MORAES, I. C,; CONCEIÇÃO, F. T.; CUNHA, C. M. L. da; MORUZZI, R. B. Comparação de metodologias na definição de fluxos acumulados a partir de modelos digitais de elevação do terreno aplicado a suscetibilidade de inundações. Revista Brasileira de Recursos Hídricos. V. 19, n. 2, p. 223-235, 2014. https://doi.org/10.21168/rbrh.v19n2.p223-235

OLIVEIRA, J. B. Solos do Estado de São Paulo: descrição das classes registradas no mapa pedológico. Campinas, Instituto Agronômico, Boletim Científico 45, 1999. 112p.

OLIVEIRA, M. A. T. de. Processos erosivos e preservação de áreas de risco de erosão por voçorocas. In: GUERRA, A. T. J. et al. (Orgs.) Erosão e conservação dos solos: conceitos, temas e aplicações. $5^{\text {a }}$ Ed. Rio de Janeiro: Bertrand Brasil, 2010, p. 58-99.

PAISANI, J. C.; OLIVEIRA, M. A. T. Desenvolvimento de incisão erosiva (voçoroca) descontínua e desconectada da rede hidrográfica em área de cabeceira de drenagem: o caso da Colónia Quero-Quero (Palmeira-PR). Revista Brasileira de Geociências, v. 31, n. 1, p. 51-58, 2017. https://doi.org/10.25249/03757536.20013115158

POESEN, J.; NACHTERGAELE, J.; VERSTRAETEN, G.; VELENTIN, C. Gully erosion and environmental change: importance 
and research needs. Catena, v. 50, n. 2-4, p. 91133, 2003. https://doi.org/10.1016/S03418162(02)00143-1

QUINN, P. F. B. J.; BEVEN, K.; CHEVALLIER, P.; PLANCHON, O. Prediction of hillslope flow paths for distributed hydrological modelling using digital terrain models. Hydrological processes, v. 5, n. 1, 1991, p. 59-79. https://doi.org/10.1002/hyp.3360050106

RIBEIRO, H. J. Análise da consistência de dados hidrológicos a partir de diferentes modelos digitais de terreno. 2015. $136 \mathrm{f}$. Dissertação (Mestrado em Engenharia do Meio Ambiente). Universidade Federal de Goiás, Goiânia, 2015.

SANCHEZ, M. C. Contribuição ao conhecimento das bases naturais dos municípios de São Pedro e Charqueada (SP). Notícia Geomorfológica: Campinas, Vol. 11 (21), p: 47-60, 1971.

SCHÄUBLE, H. HydroTools 1.0 for ArcView 3.x, 2004. Disponível em: <https://www.terracs.com/wpcontent/uploads/2018/05/hydrotoolsenglish.pdf>. Acesso em: 13 fevereiro 2020.

TAROLLI, P. High-resolution topography for understanding Earth surface processes: Opportunities and challenges. Geomorphology, v. 216, p. 295-312, 2014. https://doi.org/10.1016/j.geomorph.2014.03.008

TERNAN, J. L.; WILLIAMS, A. G.; ELMES, A.; FITZJOHN, C. The effectiveness of benchterracing and afforestation for erosion control on Raña sediments in central Spain. Land Degradation \& Development, v. 7, n. 4, p. 337-351, 1996. https://doi.org/10.1002/(SICI)1099145X(199612)7:4<337::AID-LDR238>3.0.CO;2G

THOMAZ, E. L.; RAMOS-SCHARRÓN, C. E. Rill length and plot-scale effects on the hydrogeomorphologic response of gravelly roadbeds. Earth Surface Processes and Landforms, v. 40, n. 15, p. 2041-2048, 2015. https://doi.org/10.1002/esp.3778

VALENTIN, C.; POESEN, J.; LI, Y. Gully erosion: impacts, factors and control. Catena, v.63, n. 23, p. 132-153, 2005. https://doi.org/10.1016/j.catena.2005.06.001

VALERIANO, M. M. Modelo digital de elevação com dados SRTM disponíveis para a América do Sul. São José dos Campos: INPE, 2004, 72p. 